\title{
Analisis Kinerja Operasional Ruas Jalan Satu Arah dengan Menggunakan Mikrosimulasi Vissim (Studi Kasus : Jalan Masjid Raya di Kota Makassar)
}

\author{
Operational Performance Analysis of One Way Road by using Vissim \\ Microsimulation \\ (Case Study : Masjid Raya Street in Makassar City)
}

\author{
Hasmar Halim ${ }^{1, a)}$, Ismail Mustari ${ }^{1, b)}$ \& Aisyah Zakariah ${ }^{1, c)}$ \\ 1) Jurusan Teknik Sipil, Politeknik Negeri Ujung Pandang, Ujung Pandang.
}

Korespomden : ${ }^{a}$ hasmar29@poliupg.ac.id, ${ }^{b)}$ ismailmustari65@poliupg.ac.id \&

c)aisyahzkariah@poliupg.ac.id.

\begin{abstract}
ABSTRAK
Tujuan penelitian ini adalah untuk mengetahui kinerja jalan satu arah menggunakan mikro-simulasi VISSIM dengan mengambil lokasi di Jalan Masjid Raya Kota Makassar. Sebelum melakukan simulasi, data diambil dalam bentuk volume lalu lintas, komposisi kendaraan dan kecepatan. Proses kalibrasi dapat dilakukan berdasarkan perilaku pengemudi yang diamati dengan trial and error menggunakan metode Geoffrey E. Havers (GEH) sementara proses validasi menggunakan uji statistik, uji "T". Uji coba dilakukan sampai nilai GEH yang dihasilkan mencapai $<5$. Nilai ini diasumsikan bahwa hasil simulasi telah membentuk model yang dapat mereplikasi lalu lintas ke kondisi aktual. Hasil simulasi dengan perangkat lunak menunjukkan bahwa kecepatan jalan ini $28,37 \mathrm{~km} / \mathrm{jam}, 27,08 \mathrm{~km} / \mathrm{jam}, 28,04 \mathrm{~km} /$ jam dan 31,04 km / jam dalam km / jam, pagi, siang, sore dan malam. Hasil evaluasi kinerja lalu lintas jalan raya didasarkan pada kecepatan rata-rata dari hasil simulasi kendaraan menggunakan perangkat lunak VISSIM yang didominasi oleh tingkat layanan D.
\end{abstract}

Kata Kunci : manajemen infrastruktur, manajemen operasional, jalan satu arah, mikrosimulasi VISSIM, tingkat layanan

\section{PENDAHULUAN}

Masalah transportasi merupakan masalah yang selalu dihadapi oleh negara-negara berkembang seperti Indonesia, baik di bidang transportasi perkotaan (urban transportation) maupun transportasi antar kota (rural transportation). Terciptanya suatu sistem transportasi yang menjamin pergerakan manusia, kendaraan atau barang secara lancar, aman, cepat, murah, nyaman dan sesuai dengan lingkungan sudah merupakan tujuan pembangunan dalam berbagai sektor.

Transportasi yang baik haruslah didukung oleh sarana dan prasana transportasi yang baik pula serta penyelenggaraan yang menerapkan manajemen aset infrastruktur dalam pegelolaan aset jalan di bawah kewenangannya. Manajemen operasi menjadi salah satu bagian manajemen aset infrastruktur yang bertujuan untuk memastikan tercapainya pelayananan optimal dari infrastruktur jalan (Suprayitno \& Soemitro, 2018). Faktor penting yang menentukan baik tidaknya operasional jalan adalah aspek geometri serta perkerasan jalan yang baik dan ekonomis. (Widayanti, et al., 2017). 
Pertumbuhan jalan di Kota Makassar hanya mengalami pertumbuhan sebesar $0,8 \%$ $2 \%$ pertahunnya sedangkan pertumbuhan kendaraan mencapai $15 \%$ - 16\% pertahunnya (Halim, et al., 2017). Disisi lain Kota Makassar memiliki panjang jalan nasional sepanjang $35,64 \mathrm{~km}$, jalan propinsi sepanjang 13,42 km, jalan kota sepanjang 1.527,4 km dan jalan tol sepanjang $17 \mathrm{~km}$ sehingga total panjang jalan yang ada di Kota Makassar 1.593,46 km (BPS Kota Makassar, 2014). Hal ini memberikan dampak negatif yaitu terjadinya ketidak seimbangan antara pertumbuhan kendaraan dengan pertumbuhan prasarana transportasi. Keadaan demikian tentu saja berdampak pada menurunnya kinerja lalu lintas dan tingkat pelayanan dari ruas jalan maupun persimpangan yang ada di Kota Makassar. Berbagai upaya untuk dapat mengatasi permasalahan transportasi Kota Makassar untuk menekan permasalahan ini salah satunya adalah dengan penerapan "sistem satu arah" pada ruas jalan tertentu. Di beberapa kota besar penerapan sistem ini telah banyak dilakukan terutama pada jalan protokol atau pada jalan tertentu yang memiliki tingkat kepadatan kendaraan yang tinggi. Pada beberapa kasus, kemacetan dapat diurai dengan penerapan sistem satu arah tersebut (Purwanto \& Yulipriyono, 2015; Bolla, et al., 2016; Fadillah, et al., 2013).

Salah satu ruas jalan satu arah di Kota Makassar yang memiliki volume kendaraan yang besar dan kapasitas jalan yang terbatas adalah Jalan Masjid Raya. Jalan ini merupakan jalan arteri primer yang membelah Kota Makassar dari arah Timur ke Barat. Selain kapasitas yang kurang memadai sehingga menimbulkan kemacetan di beberapa titik, ruas jalan ini memiliki tingkat kecelakaan yang cukup tinggi.

Untuk mengatasi hal tersebut maka perlu dibuat suatu analisis terkait kinerja suatu ruas jalan sehingga dapat diantisipasi perkembangan lalu lintas sekarang ini dan dimasa yang akan datang. Saat ini pedoman transportasi di Indonesia yang digunakan untuk melakukan analisis dan perancangan jalan adalah Manual Kapasitas Jalan Indonesia (MKJI 1997). Pedoman ini, sejak dirumuskan hingga sekarang ini belum dilakukan revisi untuk mengantisipasi perkembangan lalu lintas di Indonesia. Seiring dengan perkembangan transportasi di Indonesia, MKJI 1997 dianggap sudah kurang relevan sehingga perlu dievaluasi kembali (Munawar \& Winnetou, 2015).

Dengan perkembangan transportasi yang semakin berkembang dan kemajuan teknologi transportasi, maka MKJI 1997 juga dirasa harus mengikuti perkembangan yang ada. Saat ini penggunaan teknologi semakin banyak digunakan pada pekerjaan di bidang apapun. Untuk bidang transportasi Teknik Sipil, terdapat beberapa perangkat lunak salah satunya adalah software VISSIM yang berbasis simulasi lalu lintas. Verkehr in Stadten SIMulations model adalah software yang mensimulasikan lalu lintas mikroskopik, transportasi umum dan pejalan kaki. Pemodelan dan simulasi sistem transportasi kini semakin diminati karena kemudahannya dalam proses pergantian berbagai skenario dengan tetap melihat potensi yang dapat diimplementasikan di lapangan.

Salah satu keunggulan software ini adalah dapat mensimulasikan menyerupai kondisi tranportasi di lapangan, memiliki parameter yang cukup lengkap, seperti kalibrasi pada driving behavior yang dapat menyerupai karakteristik pengendara di setiap daerah. VISSIM termasuk dalam perangkat lunak dengan kategori mikroskopik yang memiliki keunggulan yaitu dapat memodelkan berbagai jenis kendaraan termasuk sepeda motor dan kendaraan tidak bermotor (Putri \& Irawan, 2015).

Dari fenomena yang telah dipaparkan sebelumnya dan untuk mengatasi hal tersebut maka perlu dibuat suatu kajian operasional dan analisis kinerja suatu ruas jalan khususnya jalan satu arah yang mempunyai tingkat kecelakaan yang tinggi. Sehingga simulasi dan kajian ini akan sangat membantu pemerintah dalam menentuan sistem yang baik dan sebagai solusi untuk mengurangi tingkat kecelakaan serta mengatasi masalah kemacetan lalu lintas di Kota Makassar. 


\section{METODE PENELITIAN}

\section{Teknik Pengambilan dan Pengolahan Data}

Data sekunder yang digunakan adalah berupa foto udara yang diambil dari Google Earth guna memudahkan dalam penggambaran/pembuatan jaringan jalan pada VISSIM dan data jumlah penduduk kota Makassar. Sedangkan data primer yang dikumpulkan adalah berupa data inventarisasi/geometrik jalan yang dilakukan secara manual menggunakan walking measure, data volume arus lalu lintas yang dihitung menggunakan metode traffic counting pada selama 12 jam dari jam 06.00-18.00 dengan menggolongkan jenis kendaraan menjadi 15 macam, data panjang antrian tiap lengan simpang yang dihitung dan diamati secara manual, serta kecepatan masing-masing jenis kendaraan yang dihitung menggunakan metode journey speed. Tipe kendaraan yang digunakan pada penelitian ini adalah sepeda (UM), sepeda motor (MC), motor bak (MC), becak (UM), andong (UM), sedan (LV), city car (LV), MPV (LV), SUV (LV), mobil bak (LV), mobil boks (LV), bus kecil (HV), bus besar (HV), truk kecil(HV), dan truk besar (HV).

\section{Tahapan Pemodelan Simulasi}

Dalam melakukan simulasi mikroskopik dengan menggunakan VISSIM, terdapat beberapa parameter yang perlu ditentukan dan diinput agar model simulasi dapat berjalan. Secara singkat, parameter yang perlu diatur untuk menjalankan model simulasi pada simpang bersinyal adalah sebagai berikut yaitu menginput background; membuat jaringan jalan; menentukan jenis kendaraan; menginput kecepatan kendaraan; menginput komposisi kendaraan; menentukan rute perjalanan; menginput komposisi rute perjalanan; menginput jumlah kendaraan; mengatur sinyal lalu lintas; menempatkan sinyal lalu lintas; melakukan kalibrasi dan validasi; menjalankan simulasi

\section{Tahapan Pemodelan Simulasi}

Kalibrasi pada VISSIM merupakan proses dalam membentuk nilai-nilai parameter yang sesuai sehingga model dapat mereplikasi lalu lintas hingga kondisi yang semirip mungkin. Proses kalibrasi dapat dilakukan berdasarkan perilaku pengemudi daerah yang diamati. Metode yang digunakan adalah trial and errordengan mengacu pada penelitian-penelitian sebelumnya mengenai kalibrasi dan validasi menggunakan VISSIM. Validasi pada VISSIM merupakan proses pengujian kebenaran dari kalibrasi dengan membandingkan hasil observasi dan hasil simulasi.

Proses validasi dilakukan berdasarkan jumlah volume arus lalu lintas dan panjang antrian. Metode yang digunakan adalah dengan menggunakan rumus dasar Chisquaredberupa rumus statistik Geoffrey E. Havers (GEH) (Gustavsson, 2007). GEH merupakan rumus statistik modifikasi dari Uji Tdengan menggabungkan perbedaan antara nilai relatif dan mutlak. Rumus $G E H$ berikut ini memiliki ketentuan khusus dari nilai error yang dihasilkan seperti pada Tabel 1. Sedangkan rumus $M A P E$ yang juga dikenal sebagai rata-rata deviasi persentase absolut tersebut adalah persentase perbedaan antara data yang sebenarnya dengan data perkiraan.

$$
\mathrm{GEH}=\sqrt{\frac{\left(\mathrm{q}_{\text {simulated }}-\mathrm{q}_{\text {observed }}\right)^{2}}{0,5 \times\left(\mathrm{q}_{\text {simulated }}+\mathrm{q}_{\text {observed }}\right)}}
$$

Dengan :

$$
\begin{array}{ll}
q_{\text {simulated }} & =\text { data volume arus lalu lintas hasil simulasi (kendaraan/jam) } \\
q_{\text {observed }} & =\text { data volume arus lalu lintas hasil observasi (kendaraan/jam) }
\end{array}
$$


Table 1. Kesimpulan dari Hasil Perhitungan Rumus Statistik Geoffrey E. Havers

\begin{tabular}{cc}
\hline $\mathrm{GEH}<5,0$ & diterima \\
\hline $5,0 \leq \mathrm{GEH} \leq 10,0$ & peringatan: kemungkinan model eror atau data buruk \\
\hline $\mathrm{GEH}>10,0$ & ditolak \\
\hline
\end{tabular}

\section{HASIL DAN PEMBAHASAN}

\section{Volume dan Kecepatan Kendaraan}

Pengukuran volume lalu lintas dilakukan dengan menghitung jumlah kendaraan yang melintasi titik pengamatan. Pengukuran volume kendaraan dan kecepatan diukur berdasarkan pengolongan kendaraan sebagaimana yang telah dijelaskan sebelumnya. Pengukuran dilakukan dalam 4 (empat) periode yaitu Pagi, Siang, Sore dan Malam. Setiap periode dilakukan pencatatan volume kendaraan selama 4 (empat) jam. Adapun volume kendaraan seperti dalam Tabel 2. Dari Tabel tersebut dapat ketahui bahwa kendaraan Golongan 1 atau kendaraan sepeda motor merupakan kendaraan yang banyak melintasi Jalan Masjid Raya. Kendaraan yang melintas dijalan ini rata-rata mencapai $4.251 \mathrm{kend} / \mathrm{jam}$. Tipe kendaraan berikutnya yang banyak melintas di Jalan Masjid Raya adalah kendaraan dengan tipe minibus. Rata-rata jenis kendaraan ini mencapai $1.283 \mathrm{kend} / \mathrm{jam}$. Sedangkan kendaraan yang masuk golongan $7 \mathrm{a}$ dan $7 \mathrm{~b}$ tidak melintasi jalan ini, disebabkan karena jalan ini merupakan kawasan bebas truk $>10$ roda.

Untuk pengukuran kecepatan kendaraan dilakukan dengan menggunakan speed gun terhadap beberapa sampel kendaraan yang melintasi titik pengukuran. Sampel kecepatan yang diambil saat 10 menit pengukuran untuk tiap jam dirata-ratakan sehingga diperoleh rata-rata kecepatan kendaraan tiap jam selama 13 jam pengukuran untuk tiap titik pengukuran. Kecepatan kendaraan untuk masing-masing jalan dapat dilihat pada Tabel 2. Kemudian kecepatan kendaraan untuk masing-masing jalan itu dirata-ratakan kembali guna mendapatkan kecepatan rata-rata keseluruhan jalan baik itu untuk semua golongan kendaraan. 
Table 2. Volume dan Kecepatan Kendaraan

\begin{tabular}{clcccccccc}
\hline \multirow{2}{*}{ No } & \multirow{2}{*}{ Golongan } & \multicolumn{3}{c}{ Volume Kend. (kend/jam) } & \multicolumn{4}{c}{ Kec. Kend. (km/jam) } \\
& & Pagi & Siang & Sore & Malam & Pagi & Siang & Sore & Malam \\
\hline 1 & Golongan 1 & 3086 & 2983 & 4631 & 6303 & 47,5 & 42,1 & 41,2 & 50,6 \\
\hline 2 & Golongan 2 & 217 & 331 & 503 & 448 & 40,4 & 43,9 & 44,1 & 47,2 \\
\hline 3 & Golongan 3 & 1209 & 1502 & 1460 & 960 & 35,5 & 25,8 & 33,1 & 39,8 \\
\hline 4 & Golongan 4 & 90 & 153 & 159 & 49 & 23,7 & 22,2 & 25,6 & 24,6 \\
\hline 5 & Golongan 5a & 2 & 2 & 4 & 3 & 21,5 & 22,5 & 22,3 & 19,7 \\
\hline 6 & Golongan 5b & 2 & 1 & 1 & 1 & 19,5 & 23,7 & 23 & 21,5 \\
\hline 7 & Golongan 6a & 7 & 19 & 33 & 7 & 22,4 & 23,1 & 22,3 & 23,3 \\
\hline 8 & Golongan 6b & 5 & 20 & 19 & 8 & 22,8 & 21,4 & 21,8 & 21,6 \\
\hline 9 & Golongan 7a & 1 & 6 & 1 & 1 & 22 & 19 & 19 & - \\
\hline 10 & Golongan 7b & 0 & 0 & 0 & 0 & - & - & - & - \\
\hline 11 & Golongan 7c & 0 & 0 & 0 & 0 & - & - & - & - \\
\hline
\end{tabular}

Sebagaimana dengan volume kendaraan pada hasil pengukuran kecepatan diketahui bahwa kecepatan kendaraan sangat rendah dan kendaraan roda dua atau sepeda motor ratarata memiliki kecepatan yang lebih cepat dibandingkan dengan kendaraan lainnya. Hal ini disebabkan kapasitas jalan tidak sebanding dengan volume kendaraan sehingga kendaraan mengalami kesulitan untuk bergerak disamping itu kendaraan sepeda motor dapat melakukan manuver kendaraan sehingga kecepatan dapat lebih cepat dari pada yang lainnya.

\section{Kalibrasi dan Validasi}

Kalibrasi dilakukan dengan metode trial and errorhingga mencapai hasil yang mendekati data observasi. Nilai parameter perilaku pengemudi diubah sesuai dengan perkiraan kondisi di lapangan yang berlaku. Proses kalibrasi ini dilakukan dengan mengubah hingga mencapai hasil yang mendekati data observasi. Parameter yang dipilih dalam proses kalibrasi adalah pada segmen Jalan Masjid, ini terdapat dan proses trial and error ditunjukkan pada Tabel 3.

Tabel3. Contoh proses kalibrasi pada Jalan Masjid Raya pada pagi hari

\begin{tabular}{lcc}
\hline \multirow{2}{*}{ Parameter yang dirubah } & \multicolumn{2}{c}{ Nilai parameter } \\
\cline { 2 - 3 } Desired position & sebelum dirubah & sesudah dirubah \\
\hline Lane change rule & Mree lane change & Free lane change \\
\hline Over Take at same line & off & yes \\
\hline Lateral distance standing & 0,2 & 0,1 \\
\hline Lateral distance driving & 1 & 1 \\
\hline Minimum headway & 0,3 & 2 \\
\hline No. observed vehicle & 4 & 2 \\
\hline Avarage standstill distance & 2 & 0.5 \\
\hline
\end{tabular}

Pada tabel berikut mengambarkan hasil untuk volume arus lalu lintas pada trialke- $n$ yang dinyatakan bahwa setelah diuji menggunakan analisis statistik uji GEH, hasilnya dapat diterima. Hal ini menunjukkan bahwa simulasi Vissim pada trial ke-n sudah menyerupai kondisi lapangan. Adapun nilai kalibrasi dan hasil kalibrasi dalam Uji GEH diperlihatkan pada Tabel 4 sebagai berikut : 
Tabel 4. Uji Geoffrey E. Havers(GEH) pada Volume Arus Lalu Lintas

\begin{tabular}{lrrrcc}
\hline Waktu & Observasi & Simulasi & $\begin{array}{c}\text { Uji } \\
\text { GEH }\end{array}$ & $\begin{array}{c}\text { Trial } \\
\text { ke- }\end{array}$ & Kesimpulan \\
\hline Pagi & 770 & 737 & 1,20 & 32 & diterima \\
\hline Siang & 836 & 791 & 1,58 & 31 & diterima \\
\hline Sore & 1135 & 1052 & 2,51 & 40 & diterima \\
\hline Malam & 1297 & 1189 & 3,05 & 87 & diterima \\
\hline
\end{tabular}

Pada proses ini, dengan menggunakan Uji GEH maka hasil simulasi diharapkan mempunyai nilai GEH sebesar $<5$. Dari Tabel 4 diperlihatkan bahwa simulasi di Jalan Masjid Raya yang dilakukan pada pagi hari nilai GEH dicapai pada trial ke 32 dengan nilai sebsar 1,20. Berturut-turut pada waktu siang, sore dan malam hari nilai GEH yang dihasilkan sebesar 1,58, 2,51 dan 3,05. Berdasarkan data di atas, dapat dilihat bahwa terdapat perbedaan jumlah kendaraan antara data yang diinput dengan data yang keluar namun tidak signifikan dan masih dapat ditolerir. Sehingga dapat diasumsikan bahwa hasil simulasi mendekati dengan observasi dilapangan.

Secara visualisasi, hasil pemodelan simulasi sebelum dikalibrasi dan setelah di kalibrasi ditampilkan pada Gambar 1. Setelah proses kalibrasi berakhir, validasi dilakukan untuk menguji kebenaran kalibrasi yang telah dilakukan.

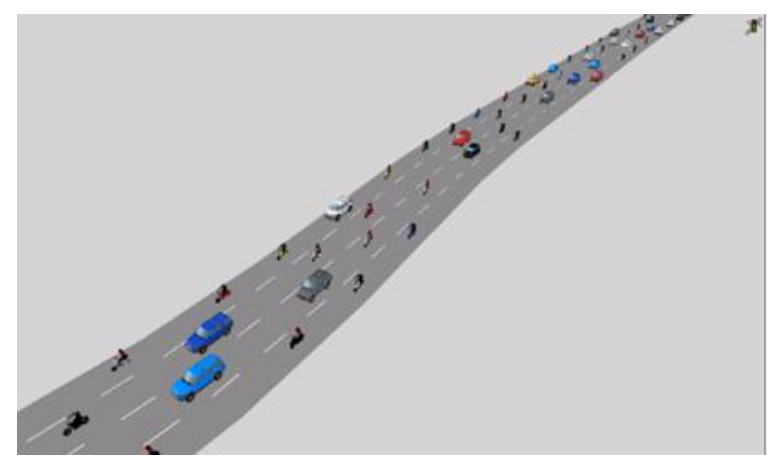

(a) Sebelum Kalibrasi

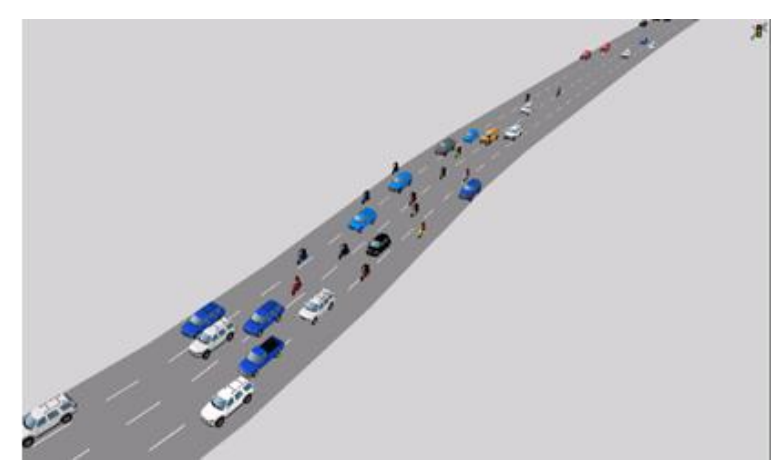

(b) Setelah Kalibrasi

Gambar1. Tampilan 3D Model Simulasi Jalan Masjid Raya Pada Pagi Hari

Pada gambar 1.a. dan 1.b. memperlihatkan tampilan visual pada software VISSIM sebelum dan sesudah kalibrasi, dimana sebelum terkalibrasi arus kendaraan sangat terteratur dan berada pada lajur masing-masing, dan jarak antar kendaraan pun sangat teratur. Sedangkan setelah terkalibrasi arus kendaraan menjadi tidak teratur dan jarak antar kendaraan begitu rapat. Hal ini menunjukkan perilaku pengemudi yang sesuai dengan kondisi dilapangan.

Setelah proses kalibrasi berakhir, validasi dilakukan untuk menguji kebenaran kalibrasi yang telah dilakukan. Proses validasi dilakukan dengan metode analisis statistik uji T. Variabel yang digunakan untuk proses validasi adalah dengan menggunakan variabel kecepatan, adapun hipotesis dalam uji ini menyatakan apakah terdapat perbedaan yang signifikan antara volume lalu lintas hasil observasi dengan hasil simulasi sebagaimana yang telah digambarkan dalam Tabel 5. Adapun perumusan hipotesa adalah sebagai berikut : 
$\mathrm{H}_{0}: \mu_{1}=\mu_{2}, \quad$ Tidak ada perbedaan rata-rata antara data hasil observasi dengan hasil simulasi $\mathrm{H}_{1}: \mu_{1} \neq \mu_{2}, \quad$ Ada perbedaan rata-rata antara data hasil observasi dengan hasil simulasi

Sedangkan hasil dari analisis statistik uji T seperti pada Tabel 8 berikut ini :

Tabel 5. Hasil Validasi dengan Uji $\mathrm{T}$ padaKecepatan lalu lintas

\begin{tabular}{|l|c|c|c|c|}
\hline \multirow{2}{*}{ Hasil } & \multicolumn{4}{|c|}{ Kecepatan (km/jam) } \\
\cline { 2 - 5 } & Pagi & Siang & Sore & Malam \\
\hline Observasi & 28,37 & 27,08 & 28,04 & 31,04 \\
\hline Simulasi & 29,29 & 28,31 & 27,93 & 30,97 \\
\hline$T$-Hitung & \multicolumn{4}{|c|}{$-1,437$} \\
\hline$T$-tabel & \multicolumn{4}{|c|}{2,353} \\
\hline$\rho$-value & \multicolumn{4}{|c|}{0,246} \\
\hline Kesimpulan & \multicolumn{4}{|c}{ Diterima } \\
\hline
\end{tabular}

Dari Tabel 5 diketahui bahwa $\mathrm{T}_{\text {hitung }}$ pada taraf signifikansi 0,05 dengan derajat kebebasan sebesar 3 sebesar -1,437 sedangkan pada taraf signifikansi dan derajat kebebasan yang sama diketahui $\mathrm{T}_{\text {tabel }}$ mempunyai nilai sebesar 2,353, maka dapat disimpulkan bahwa $\mathrm{T}_{\text {hitung }}<\mathrm{T}_{\text {tabel }}$ atau $\mathrm{H}_{0}$ diterima yang berarti tidak ada perbedaan rata-rata antara data hasil observasi dengan hasil simulasi. Begitu juga dengan nilai probabilitas ( $\rho$-value) yang ditunjukkan dalam Tabel 5 diketahui sebesar 0,246 nilai ini lebih besar dari 0,05 ( $\rho$-value > $0,05)$ dengan demikian dapat disimpulkan bahwa $\mathrm{H}_{0}$ diterima. Dengan demikian berarti model simulasi memenuhi syarat yang berarti tidak ada perbedaan yang signifikan antara kecepatan observasi dengan kecepatan simulasi sehingga dengan demikian model simulasi dinyatakan valid.
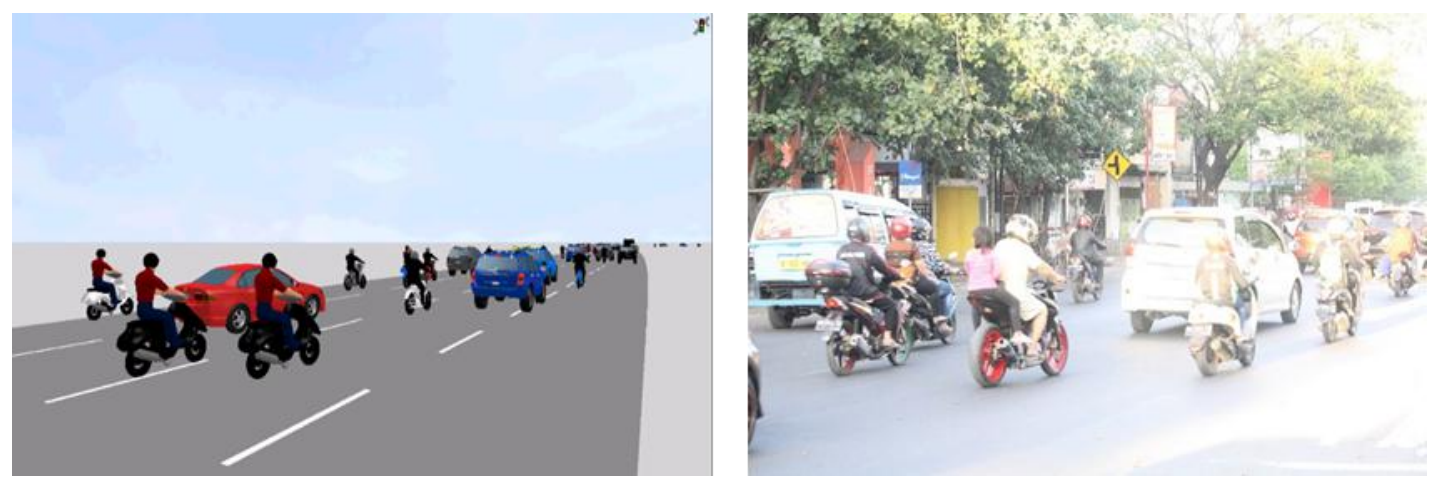

Gambar2. Visualisasi 3D di Jalan Masjid Raya

Visualisasi yang ditampilkan pada Gambar 2 merupakan contoh kondisi visualisasi pada lokasi studi yaitu di Jalan Masjid Raya yang memperlihatkan model simulasi tidak terlalu jauh berbeda dengan gambaran di lapangan dimana posisi kendaraan serta jarak antar kendaraan depan belakangan maupun samping kiri kanan sudah menunjukkan posisi yang hampir serupa. Ini berarti model simulasi yang telah dibuat sudah valid. 


\section{Evaluasi Tingkat Kinerja}

Dari hasil parameter pada Tabel 6 kemudian akan digunakan untuk mendapatkan tingkat pelayanan dari ruas Jalan Masjid Raya. Evaluasi yang dilakukan yaitu dengan mengambil nilai kecepatan rata-rata kendaraan pada output VISSIM. Dari tabel kecepatan tersebut kemudian digunakan untuk mendapatkan tingkat pelayanan dengan mengacu pada nilai kecepatan ideal berdasarkan Peraturan Menteri Perhubungan No. KM: 14 Tahun 2006. Adapun tingkat pelayanan Jalan Masjid Raya berdasarkan kecepatan yang dihasilkan seperti pada tabel berikut ini.

Tabel 6. Tingkat Pelayanan Jalan Masjid Raya

\begin{tabular}{|l|c|c|c|c|}
\hline \multirow{2}{*}{\multicolumn{1}{|c|}{ Nama Jalan }} & \multicolumn{4}{|c|}{ Tingkat Pelayanan } \\
\cline { 2 - 5 } & Pagi & Siang & Sore & Malam \\
\hline Kecepatan & 29,29 & 28,31 & 27,93 & 30,97 \\
\hline Tingkat Pelayanan & D & D & D & C \\
\hline
\end{tabular}

Dari tabel diatas dapat dilihat bahwa pada ruas jalan Mesjid Raya didominasi tingkat pelayanan D dengan kondisi arus lalu lintas yang mendekati tidak stabil.

\section{KESIMPULAN}

Dari hasil dan pembahasan terkait karakteristik dan tingkat pelayanan Jalan Masjid Raya maka dapat ditarik beberapa kesimpulan sebagai berikut :

- Karakteristik lalu lintas pada setiap ruas Jalan Masjid Raya diketahui volume lalu lintas berturut-turut sebesar $4619 \mathrm{kend} / \mathrm{jam}, 5017 \mathrm{kend} / \mathrm{jam}, 6811 \mathrm{kend} / \mathrm{jam}$ dan sebesar 7780 $\mathrm{kend} / \mathrm{jam}$ serta kecepatan rata-rata yang terjadi pada ruas jalan ini sebesar $28,37 \mathrm{~km} / \mathrm{jam}$, $27,08 \mathrm{~km} / \mathrm{jam}, 28,04 \mathrm{~km} / \mathrm{jam}$ dan $31,04 \mathrm{~km} / \mathrm{jam}$ pada waktu pagi, siang sore dan malam hari.

- Hasil evaluasi kinerja lalu lintas ruas Jalan Masjid raya didasarkan dengan kecepatan rata-rata kendaraan hasil simulasi dengan menggunakan software VISSIMdidominasi tingkat pelayanan D.

CATATAN. Terima kasih banyak kepada Antonius Herry Indrawan dan Akhmaluddin yang telah membantu dalam proses pengambilan data dan pengolahan data.

\section{DAFTAR PUSTAKA}

Bolla, M. E., Messah, Y. A., \& Laning, R. L. (2016). Analisa Dampak Penerapan Sistem Lalu Lintas Satu Arah Pada Simpang 3 Strat-A Terhadap Arus Lalu Lintas Serta Kinerja Lahan Parkir Di Pasar Tradisional Oeba Kota Kupang. Jurnal Teknik Sipil,, V(2), 199212.

BPS Kota Makassar. (2014). Makassar Dalam Angka 2013. Makassar: Kerjasama Badan Perencanaan Pembangunan Daerah Dan Badan Pusat Statistik Kota Makassar.

Fadillah, R., Firdaus, O., \& Sabri, F. (2013). Pengaruh Penerapan Jalan Satu Arah Terhadap Jalan Kolektor Sekunder (Studi Kasus Pada J1. Kh. Abdul Hamid Dan Jl. Kh Abdurrahman Siddik Di Kota Pangkalpinang). Jurnal Fropil, 1(2), 125-133.

Gustavsson, F. (2007). New Transportation Research Progress. New York: Nova Science Publishers. 
Halim, H., Adisasmita, S. A., Ramli, M., \& Aly, S. H. (2017). The Pattern Of Severity Of Traffic Accident On Traffic Conditions Heterogeneous. International Journal Of Civil Engineering And Technology (Ijciet), 1720-1729.

Munawar, A., \& Winnetou, I. A. (2015). Penggunaan Software Vissim Untuk Evaluasi Hitungan Mkji 1997 Kinerja Ruas Jalan Perkotaan (Studi Kasus : Jalan Affandi, Yogyakarta). The 18th Fstpt International Symposium, Unila. Bandar Lampung: Fstpt.

Purwanto, D., \& Yulipriyono, E. E. (2015). Efektifitas Pemberlakuan Sistem Satu Arah Pada Jalan Indraprasta Kota Semarang Dalam Rangka Pemerataan Sebaran Beban Lalu Lintas. Jurnal Media Komunikasi Teknik Sipil, 21(1), 47-55.

Putri, N. H., \& Irawan, M. Z. (2015). Mikrosimulasi Mixed Traffic Pada Simpang Bersinyal Dengan Perangkat Lunak Vissim. The 18th Fstpt International Symposium, Unila. Bandar Lampung: Fstpt.

Suprayitno, H. \& Soemitro, R.A.A (2018). "Preliminary Reflexion on Basic Principle of Infrastructure Asset Management". Jurnal Manajemen Aset Infrastruktur \& Fasilitas, Vol.2, No.1, Maret 2019, Hal. : 1-10.

Widayanti, A., Soemitro, R. A., Putri, J. J., \& Hitapriya, S. (2017). Karakteristik Material Pembentuk Reclaimed Asphalt Dari Jalan Nasional Di Provinsi Jawa Timur. Jurnal Manajemen Aset Infrastruktur \& Fasilitas, 1(1), 45-55. 
(e)ISSN 2615-1847 $\quad$ (p)ISSN 2615-1839

Jurnal Manajemen Aset Infrastruktur \& Fasilitas - Vol.3, No.2, September 2019 